\title{
El ciberespacio y el problema de la realidad virtual
}

Andrea Arbeláez Giraldo

Universidad Nacional de Colombia

(c) $\underset{\mathrm{Br}}{\mathrm{i}}$ 


\section{El ciberespacio y el problema de la realidad virtual}

Resumen: al encontrar que las primeras reflexiones acerca del ciberespacio se hallan, no en los estudios académicos, sino en la literatura y en el cine, se parte de un breve análisis de la novela Neuromante, de William Gibson, y de la trilogía Matrix, de los hermanos Wachowski, para abordar, mediante conceptos aportados por autores como Peter Sloterdijk (Esferas, Actio in distans), Jacques Derrida (Khôra), Jean Baudrillard (Híper-Realidad), Pierre Lévy (Ciberespacio y Virtualidad) y Gilles Deleuze (Virtual/Actual, Real/Posible), algunos de los problemas que conlleva la caída en el ciberespacio.

Palabras clave: ciberespacio, cíber-esfera, cibernauta, espacio digital, realidad virtual, híper-realidad.

\section{The cyberspace and the problem of virtual reality}

Abstract: finding that the first reflections about cyberspace are not in academic studies, but in literature and film, is part of a brief analysis of the Neuromancer novel by William Gibson, and the Matrix trilogy by the Brothers Wachowski, to approach, through concepts contributed by authors such as Peter Sloterdijk (Spheres, Actio in distans), Jacques Derrida (Khôra), Jean Baudrillard (Hyperreality), Pierre Lévy (Cyberspace and Virtuality) and Gilles Deleuze (Virtual / Actual, Real / Possible), some of the problems associated with the fall in cyberspace.

Keywords: Cyberspace, cyber-sphere, netizen, digital, virtual reality, híperreality.

Fecha de recepción: 17 de abril de 2017

Fecha de aceptación: 31 de mayo de 2017

Forma de citar APA: Arbeláez Giraldo, A. (2017). El ciberespacio y problema de la realidad virtual. Revista Filosofía UIS, 16(2), doi: http://dx.doi.org/10.18273/revfil. v16n2-2017009

Forma de citar (Harvard): Arbeláez Giraldo, A. (2017). El ciberespacio y problema de la realidad virtual. Revista Filosofía UIS, 16(2), 173-195.

Andrea Arbeláez Giraldo: colombiana. Psicóloga, Magíster en Estética, Profesional de Área de Cultura y Desarrollo Humano en Comfama.

Correo electrónico: a.arbelaezg@gmail.com

* Artículo de reflexión derivado de investigación. 


\section{El ciberespacio y el problema de la realidad virtual}

Operaba en un estado adrenalínico y casi permanente, un derivado de juventud y destreza, conectado a una consola de ciberespacio hecha por encargo que proyectaba su incorpórea conciencia en la alucinación consensual que era la matriz

(Gibson, 2006, p. 1).

Matrix te posee. Tú te crees dueño de tu vida, de tus acciones, de todas esas pequeñas o grandes cosas que haces cada día, pero... ¿Cómo podrías demostrar que todo esto no es una ilusión? ¿Nunca has tenido un sueño que pareciera muy real? ¿Cómo sabrías entonces diferenciar sueño de realidad? El hacer creer que se vive una existencia normal es un poder muy grande, una forma de control terrible

(Wachowski, 1999).

La primera utilización de la expresión Ciberespacio se encuentra, probablemente, no en los estudios académicos, sino en la literatura, más específicamente, en la novela de ciencia ficción Neuromante de Gibson, que fuera publicada en 1984. El escritor empleó esta palabra para referirse a un espacio digital construido por muchos computadores en red, al que sólo podía accederse desde una terminal personal, mediante goggles y conexiones electrónicas entre el ordenador y el sistema nervioso, que permitía a los usuarios ingresar a una onírica mátriz que operaba como una "alucinación consensual".

Con el texto citado en el primero de los epígrafes comienza William Gibson su novela Neuromante (Gibson, 2006, p. 1), para describir el estado de una sociedad inclinada, cada vez más, hacia el interior, el encierro, la privacidad y el aislamiento propiciado por los ordenadores que permiten alejarse de los espacios comunes y del afuera. Este volcamiento hacia adentro nos permite acceder a un mundo que se ha gestado entre medios y dispositivos electrónicos que permiten ingresar y experimentar esta nueva dimensión que logra articular de un nuevo modo la humanidad con la tecnología. En esta dimensión, las relaciones se entretejen mediante una pantalla de computador o un teléfono móvil inteligente, aparatos 
que operan como terminales para poder acceder al ciberespacio y experimentar las potencialidades construidas por la humanidad, a partir de la tecnología. Como se puede advertir, William Gibson logró escribir una novela visionaria en la que, sin proponérselo, postuló nociones fundamentales para la descripción e interpretación de un fenómeno que se avecinaba y llegaría a su plenitud casi dos décadas más tarde. Los autores que abordarían los problemas de la sociedad de la información, la era del conocimiento y el uso de los dispositivos tecnológicos, inevitablemente se verían obligados a retomar estas nociones en el proceso de elaboración de sus planteamientos, de modo que resultasen más adecuados a las realidades de que trataban. ¿Cómo no servirse de las intuiciones de la literatura para teorizar sobre los nuevos problemas e ilustrar a los lectores acerca de asuntos tan complejos y tan distantes del mundo tangible al que estaban habituados?

Para lograr comprender mejor el alcance de la producción literaria de Gibson, en lo que al ciberespacio se refiere, vamos a examinar algunas de las nociones que planteó en su novela, para contrastarlas con el uso que actualmente se les da en el argot tecno-científico. En primer lugar, el novelista concibe el ciberespacio como un espacio digital, pese a que en su época todavía no se tenía claridad sobre el significado de esta expresión. El autor la empleó para referirse al mundo virtual que comenzaba a configurarse, al que se accedía mediante ciertas conexiones electrónicas y ya daba señales de tener un gran potencial frente a los condicionamientos de nuestra realidad tangible. En su novela, el escritor norteamericano pudo recrear un mundo digital tan verosímil que hace evidente la posibilidad de que en un futuro cercano, la información podría llegar a ser tan valiosa como la materia o la energía -o quizás más-, convirtiéndose en una especie de ADN del ciberespacio. Es bastante llamativo, además, que las mismas palabras que un escritor de ciencia ficción emplease para ilustrar y dar vida a su historia futurista, años más tarde pasarán a ser nociones propias del vocabulario vigente, en lo relativo al ciberespacio. Así encontramos que en el Neuromante se emplea la palabra goggles para referirse a unos dispositivos que permitían conectarse desde el sistema nervioso para navegar en el espacio virtual. Esta expresión, en absoluto es lejana a nuestra realidad actual, pues existe google goggles, una aplicación para sistemas operativos Android, que permite reconocer distintos objetos mediante fotos tomadas con un móvil, en las cuales se accede a resultados de búsqueda e información relacionada.

En el año 2011, William Gibson fue entrevistado por el Paris Review. Allí el escritor de ciencia ficción relata cómo llegó a postular estas palabras y, sobre todo, la noción de ciberespacio, que actualmente es aceptada y usada mundialmente, y que él había visualizado como un espacio nocional que permitía ingresar a otro universo: 
Estaba caminando por Vancouver, consciente de esa necesidad, y recuerdo que pasé por un salón de juegos de video, una especie de nuevo negocio en ese entonces, y vi a chicos jugando esos viejos juegos de video con consolas multilaminadas. Los juegos tenían una representación gráfica muy primitiva del espacio y la perspectiva. Algunos ni siquiera tenían perspectiva pero añoraban ya una perspectiva y una dimensionalidad. Aún en esta forma tan primitiva, los chicos jugando estaban tan involucrados físicamente, que me pareció que querían estar adentro de los juegos, dentro del espacio nocional de la máquina. El mundo real había desaparecido para ellos - había perdido toda importancia. Estaban en ese espacio nocional y la máquina enfrente de ellos se había convertido en el nuevo mundo feliz (Wallace-Wells, 2011).

Ciertamente, Gibson no será un experto en cuestiones de ciberespacio; sin embargo, no deja de sorprender que su concepción de espacio digital pudiera anticipar tantos aspectos del problema que los teóricos de la materia han planteado después. No cabe duda de que el escritor norteamericano esboza adecuadamente las relaciones que se tejen entre el mundo físico y esa otra dimensión con la que estamos actualmente tan familiarizados, que se despliega en el mundo digital, al cual se accede mediante una gran variedad de dispositivos tecnológicos.

Retornando a su ideación del ciberespacio, tenemos que el escritor norteamericano lo describe como una Matriz, es decir, como "una representación gráfica de información abstraída de los bancos de todos los ordenadores del sistema humano. Una complejidad inimaginable. Líneas de luz clasificadas en el no-espacio de la mente, conglomerados y constelaciones de información" (Gibson, 2006, p. 26). Al conectarse con la Matriz, los cibernautas acceden a un universo de redes numéricas que se torna en un lugar de intercambios, encuentros y aventuras, donde su accionar permite que lleguen a relacionarse con otros usuarios y con algunas organizaciones, experimentando sensaciones tan vívidas como las de la realidad tangible.

El problema surge cuando el ciberespacio deviene en fuente de conflictos de interés, en tanto comienza a funcionar como una nueva frontera política y económica. Paralelamente, Case, el protagonista, comienza a percibir como reales los efectos alucinantes de sus acciones en la matriz, y llega al punto de no poder diferenciar claramente en qué momento se encuentra conectado en el ciberespacio y cuándo no, describiendo así su experiencia:

El ciberespacio. Una alucinación consensual experimentada diariamente por billones de legítimos operadores, en todas las naciones, por niños a quienes se enseña altos conceptos matemáticos... Líneas de luz clasificadas en el no-espacio de la mente, conglomerados y constelaciones de información. Como las luces de la ciudad que se aleja... (Gibson, 2006, p. 26). 


\section{Paradojas del ciberespacio}

Puede decirse que en la ciencia ficción comienzan a vislumbrarse los problemas derivados de la llegada de una realidad inminente para la humanidad: el desarrollo a gran velocidad de la tecnología digital y su, cada vez mayor, incorporación a la sociedad y la vida de las personas. De hecho, esa problemática relación entre humanidad y tecnología descrita por William Gibson en el Neuromante, fue llevada, quince años después, a la pantalla grande, por Laurence «Larry» y Andrew Paul «Andy» Wachowski, más conocidos como los hermanos Wachowski, en su exitosa trilogía Matrix ${ }^{1}$, esa alucinante alegoría del ciberespacio.

La trama aparente de estas películas sería la resistencia humana contra los efectos perversos de la tecnología cibernética. Sus protagonistas serían un grupo de personas que se habrían organizado para hacer frente al sino depredador de las máquinas, tratando de ingresar clandestinamente a la Matrix ${ }^{2}$. El objetivo de los rebeldes es rescatar a todo aquel que sospeche que algo no anda bien en ese mundo artificial que habita sin saberlo, para -después de desconectarlo y obtener su aprobación- llevarlo a la ciudad subterránea de Zion donde conviven las personas libres y las liberadas, las cuales alcanzan una especie de logro supremo, por ser ellos mismos quienes aparentemente definen su propio destino, a diferencia de los alienados que permanecen conectados a la red.

De esta forma, se nos presenta un futuro en el que casi todas las personas son sometidas por máquinas y robots, tras varios siglos de una guerra implacable entre seres humanos e inteligencias artificiales autónomas y muy poderosas. Básicamente, esta historia nos muestra un hipotético mundo por venir, dentro de unos doscientos años o, quizás, más, en el que las inteligencias artificiales dominan la tierra y donde los papeles se han invertido: no son las máquinas las que están al servicio de los hombres, sino los hombres los que se encuentran al servicio de las máquinas. Convertidos en baterías vivientes, los seres humanos son cultivados por las máquinas con el fin de extraerles la energía que éstas necesitan para poder funcionar en un mundo despojado de los rayos solares. Para poder explotarlos sin herir susceptibilidades que pudiesen suscitar la rebelión, se las ingenian para sumergirlos dentro de unas cápsulas que, de manera análoga a una placenta, contienen una especie de líquido amniótico en donde los cuerpos se ven condenados a flotar durante toda su vida, cual fetos empedernidos que dormitan plácidamente dentro del útero materno, mientras están inmersos en

\footnotetext{
La trilogía consta de las siguientes películas: The Matrix (1999), The Matrix Reloaded (2003), The Matrix Revolutions (2003).

${ }^{2}$ Como se verá, usaremos la expresión "la Matrix" para referirnos a la cíber-microesfera que funciona como un simulacro del mundo de finales del siglo XX, y "Matrix" -a secas- para referirnos a la película, que en sí misma constituye una cíber-macroesfera que comprende todas las cíber-microesferas que aparecen en ella. Los conceptos de microesfera y macroesfera, que hemos tomado del filósofo alemán Peter Sloterdijk, serán abordados más adelante.
} 
una especie de trance hipnótico controlado que -convenientemente- recrea el mundo tal y como es en el momento mismo en que se realiza la película. El propósito sería evitar el despertar que provocaría la desconexión y viceversa, de las pilas humanas.

La Matrix, que consistiría en un simulacro de la sociedad finisecular y finimilenaria -la nuestra-, como ya se dijo, constituye un mundo digital -una realidad virtual- que se presenta ante sus víctimas como si fuese el mismísimo mundo real -o tangible-. En aquel mundo digital, aparentemente, vivirían personas que, realmente, se encontrarían suspendidas en unas terminales que los mantendrían conectados a la red, mientras las máquinas se alimentarían de su vitalidad o energía. En efecto, la Matrix se despliega como un no-lugar, cuya espacialidad está determinada por los códigos de programación informática que configuran el contenido seudomaterial de la cíber-microesfera habitada virtualmente por las personas conectadas, con toda la experiencia de sus sentidos incluida. Pero el sistema presenta una anomalía que, paradójicamente, evita que todo funcione de acuerdo con un modelo determinista que lo condene al estancamiento, introduciendo el azar que hace posible la irrupción de lo impredecible. Es así como se explica la dificultad que podrían experimentar aquellos habitantes involuntarios del ciberespacio para interpretar ese mundo virtual -la cíber-microesfera- en el que están inmersas sus mentes, como si fuese su mundo tangible -en el que están encadenados sus cuerpos-, ya que el simulacro no es perfecto: De hecho, en algunos se despiertan ciertas sospechas, como es el caso de Neo, uno de los protagonistas. Como muchos otros antes que él, Neo es desconectado -previa consulta- y recibe de Morfeo -otro de los protagonistas- la bienvenida al desierto de lo real. A partir de su despertar, Neo se ve compelido a contraponer ese sórdido mundo real -que irrumpe en su vida con el estado de vigilia al que acaba de acceder- con aquel otro mundo que le era tan familiar y que hasta entonces creyó real -la Matrix-, el cual, comparado con el que ahora aparece como real, bien podría considerarse un mundo feliz, en todo el sentido de la expresión ${ }^{3}$. Pero en razón del problema que estamos tratando, hay que decir que -a pesar de las tentaciones- vamos a cuidarnos de buscar cualquier otra coincidencia -que las hay- con la novela homónima de Huxley o -incluso- con 1984 de Orwell y con otras más, ya que esa es otra cuestión. Lo mismo haremos con cualquier otra referencia intertextual no pertinente, ya que Matrix -la película- es rica en simbolismos míticos, religiosos, filosóficos y literarios.

Como se vio antes, en la entrevista concedida por Gibson en el 2011, el autor del Neuromante hace alusión al tema cuando se refiere al momento en que experimentó la epifanía del ciberespacio. 
Ahora bien, como en todo proceso de desprogramación mental, el asunto no resulta tan sencillo. Neo se ve obligado a aprender -con mucho esfuerzo- que, en tanto las leyes de la Matrix no son reales -o mejor dicho, físicas- sino virtuales ${ }^{4}$ -y que, por lo tanto, se trata de un mundo alegórico-, puede controlarlas con su mente, violentándolas si es preciso. Ahora Neo es consciente de que cuando se conecta a la Matrix, la Matrix se introduce dentro de su mente y su mente se introduce dentro de la Matrix, produciéndose un contacto entre dos realidades virtuales: la artificial -de las máquinas-y la natural -de su mente-, por lo que se encuentra ante una disyuntiva: o controla o es controlado. Lo asombroso viene después, cuando Neo -que ya ha asumido el papel mesiánico de salvador de la humanidad, al reconocerse como el elegido- descubre que su poder también tiene cobertura sobre su mundo real. A partir de ahí, ya todo está claro, y cualquier cosa que suceda después no hace más que confirmarlo: todo en Matrix es virtual; tanto lo que sucede dentro de la Matrix -la cíber-microesfera-, como lo que sucede fuera de ella pero está dentro de Matrix -la cíber-macroesfera-. El volcamiento hacia adentro es total: en Matrix no existe un afuera. La clave es Neo, personaje descaradamente teleológico que -como el personaje de la película La última tentación de Cristo ${ }^{5}$ - se ve compelido a cumplir una misión de la cual no puede escaparse; que increíblemente posee poderes dentro y fuera de la Matrix, y del cual se informa que han existido varias versiones anteriores y existirán otras posteriores, según le revela el Arquitecto -personaje que evoca el principio masculino de la alquimia y, por supuesto, también al dios de los masones- al Oráculo -su contrapartida femenina en la dialéctica del juego-, al final de la última película de la trilogía: The Matrix Revolutions.

Por supuesto, siempre quedará la duda de si el Arquitecto y el Oráculo no son otra cosa que sendos avatares de usuario de dos jugadores externos a Matrix que, como en el poema Ajedrez de Borges ${ }^{6}$, son controlados por la mano invisible de estos (recuérdese el eterno dilema de los personajes: ideterminismo o libertad?), quienes, a su vez, también pueden ser controlados por una mano superior a ellos, como si estuviesen inmersos en un orden creciente de círculos concéntricos, en donde se sube de nivel a medida que el círculo cambia su condición de continente a contenido, es decir, aumenta de tamaño, a la manera de esas muñecas rusas conocidas como matrioskas. Pero en este punto habremos de confesar nuestro agnosticismo: eso no se puede saber. Aunque sí existe algo acerca de lo que no tenemos ninguna duda: el verdadero protagonista de la película es el ciberespacio.

\footnotetext{
${ }^{4}$ Es necesario aclarar que si oponemos lo real a lo virtual en este contexto, ello se debe a que esa es la oposición que se lleva a cabo en la película comentada. Nosotros entendemos que lo virtual también es real, aunque de otro modo, y que lo que solemos llamar real es lo que también se llama actual o tangible.

${ }^{5}$ La cual, como se sabe, lleva a la pantalla grande la novela homónima del escritor griego Nikos Kazantzakis.

${ }^{6}$ Ver anexo.
} 


\section{El ciberespacio como esfera}

No es necesario insistir en las coincidencias que existen entre la película Matrix y la novela Neuromante, en la cual, como se pudo ver, mutatis mutandis, también había una Matriz. Sin embargo, antes de continuar, es conveniente aclarar en qué sentido hemos afirmado que el ciberespacio da lugar a la conformación de microesferas y macroesferas en su interior, como se puede apreciar en la película Matrix.

Los conceptos de microesfera y macroesfera los hemos tomado -como se sabedel filósofo alemán Peter Sloterdijk. De acuerdo con este autor, las esferas serían unos espacios sistémico-inmunológicamente efectivos, que acogerían al hombre para protegerlo y abrigarlo del frío gélido del afuera. El concepto de esfera permite dar cuenta de los avatares de la espacialización que despliega el hombre cuando encara su existencia insondable y debe asumir su vulnerabilidad frente al asedio del afuera; problema que resuelve habitando diversas esferas. El movimiento de la existencia recorrería diferentes esferas, comenzando con la burbuja simbiótica materno-fetal, pasando luego por otras construcciones esféricas intermedias, como la familia, la escuela y la comunidad, hasta llegar a la macroesfera global planetaria. De acuerdo con esta teoría, desde que comienza a existir, el hombre vive en esferas, es decir, habita unas formas de organización espacial que lo protegen de ese afuera al que fue arrojado. Es necesario insistir en que las esferas surgen como espacios de existencia y de coexistencia y que, en su forma fundamental, se encuentra la díada madre-hijo, o esfera primigenia. Una vez se sale de la esfera uterina, el neonato queda expuesto al afuera y comienza a protegerse resguardándose en esferas, que serán cada vez más complejas. Esta organización espacial tiene su origen en una suerte de drama esferológico del desarrollo, marcado por el paso del campo uterino, de dúplice unicidad, al desarraigo del afuera colmado de mundos multipolares. Los individuos que hacen el tránsito, o salen de la microesfera uterina, dan un paso al afuera porque "se separan de su condición infantil en tanto que cesan de vivir completamente a la sombra del otro identificado y comienzan a ser habitantes de una esfera psicosocial ampliada" (Sloterdijk, 2003, p. 59). Cuando la existencia comienza a desplegarse en la esfera psicosocial surge el exterior, aquello que, bajo ninguna circunstancia, podrá convertirse en propio, es decir, en interior. No obstante, cada nuevo habitante de la macroesfera psicosocial trae consigo una suerte de patrimonio, conformado por aquellos recuerdos de la esfera simbiótica originaria y la dúplice unicidad que allí se establecía. En este sentido, el orden de la existencia estaría marcado por un tránsito desde el interior hasta el exterior, pero siempre en esferas. A medida que el individuo crezca y se vaya configurando como un ser autónomo, irá ampliando su espacio de relación a otras esferas. Pasará de la esfera familiar a otras formas de organización social más complejas y amplias, que irán moldeando su existencia. En cualquier caso, ya se trate de la burbuja dual o del máximo imperial, las esferas permiten comprender el espacio humano por la coexistencia -o la cercanía- que produce un interior a partir del estarjuntos. Sloterdijk señala que "llamamos a ese interior la microesfera y lo caracterizamos 
como un sistema de inmunidad espacial anímico (moral, si se quiere), muy sensible y capaz de aprender" (Sloterdijk, 2009, p. 15). De acuerdo con esta propuesta, la base de toda relación entre interior y exterior, está sobre lo relacional y no, como solía creerse, sobre el individuo. El interior no sería algo exclusivo del ser, sino que se iría constituyendo a partir de las relaciones, comenzando por la establecida entre madre e hijo en aquella microesfera primigenia.

Ahora bien, si se admite que se puede considerar el ciberespacio como un nuevo tipo de esfera, es válido emplear el neologismo cíber-esfera para hacer referencia a aquellos espacios virtuales que surgen entre los usuarios de la web y que se instauran como nuevas dimensiones de la vida social. Tanto es así que se puede observar cómo en la cíber-esfera se gestan unos ciertos lugares que acogen a las personas y les ofrecen la posibilidad de desplegar una multiplicidad de interacciones e intercambios y, con estos, insólitas formas de devenir.

\section{Un lugar paradójico}

La pregunta es qué tipo de lugar es ese nuevo lugar y la respuesta no puede dejar de sorprendernos, pues no se trata de un lugar, en el sentido convencional, sino, más bien, de un no-lugar en donde, no obstante, se concretan encuentros. Volviendo al Neuromante y a Matrix, encontramos que en estas dos obras se escenifica un no-lugar que, curiosamente, evoca ciertos pasajes del diálogo el Timeo de Platón, donde se introduce la noción de Khôra, la cual, como se verá, adquiere una gran relevancia a la hora de abordar la cuestión del ciberespacio. Jacques Derrida retorna a este diálogo platónico, dedicando un breve escrito a la definición y comprensión de la palabra griega, donde expresa que "el Timeo nombra khôra (localidad, lugar, espaciamiento, emplazamiento) a esa «cosa» que no es nada de aquello a lo cual, sin embargo, parece «dar lugar», sin dar jamás nada" (Derrida, 2011, p. 11). Esta definición puede extrapolarse desde el diálogo platónico hasta las dos obras anteriormente mencionadas: el Neuromante y Matrix. En ambas se describe una onírica matriz, cuyas cualidades, en definitiva, pueden equipararse a las de khôra, sobre todo en lo que se refiere a su posibilidad de dar lugar a pesar de ser un no-lugar.

Si consideramos el ciberespacio como un no-lugar que configura la posibilidad de establecer relaciones, interacciones e intercambios, podemos atribuirle una condición semejante a la de khôra, en el sentido en que la entiende Derrida:

La Khôra no es ni «sensible» ni «inteligible»: pertenece a un «tercer género» («triton genos», 48e, 52a). Ni siquiera puede decirse de ella que no es ni esto $n i$ aquello, o que es a la vez esto y aquello. No basta recordar que no nombra ni esto ni aquello, o que dice esto y aquello. La ambigüedad declarada por Timeo se manifiesta de otro modo: la khôra parece tan pronto no ser ni esto ni aquello como ser a la vez esto y aquello (Derrida, 2011, p. 16). 
Esa indeterminación entre lo sensible y lo inteligible puede aplicarse a la condición virtual del ciberespacio, en tanto ser en potencia y no ser en materia tangible. En este punto de nuestro análisis, es indispensable poner en claro que plantear la condición virtual del ciberespacio no implica afirmar que éste sea irreal, por no ser palpable, sino que, más bien, abre la posibilidad de explorar otras potencialidades de expansión del ser en una dimensión digital, que también experimentamos mediante la sensibilidad y la percepción -aunque de otro modoy que, por supuesto, también podemos habitar -desde luego, también de otro modo-. A pesar de no poder asociar el ciberespacio con una ubicación geográfica -un lugar-, el universo que despliega cumple la función de una dimensión virtual que posee las características de una dimensión real sin geografía.

La dimensión virtual del ciberespacio simula, con una perfección cada vez mayor y una cobertura cada vez más amplia, los rasgos aparentes de la dimensión tangible, echando mano de todos los recursos cibernéticos disponibles para generar una híper-realidad (Baudrillard, 1984) que permite coexistir el espacio tangible con el virtual, hasta el punto de producir la sensación de que la experiencia de habitar el primero se mejora a partir de la experiencia vivencial del segundo, que podría parecer más rica, interesante, gratificante y, en todo caso, más intensa. De allí su atractivo irresistible para los grandes públicos. Pero aquí surge una nueva cuestión: ¿cómo definir la frontera entre el adentro y el afuera?

\section{El ciberespacio, un tejido social}

El ciberespacio, en efecto, se configura como un espacio social estructurado a partir de los actores que lo constituyen, reflejando, configurando o desfigurando las dinámicas de la dimensión externa a su universo, es decir, de la realidad tangible. John Perry Barlow ilustra esta idea con bastante claridad en su Declaración de independencia del ciberespacio (Barlow, 1996), donde hace referencia a un lugar [sic] que surge como una construcción colectiva que no obedece a ninguna soberanía estatal y que podría considerarse como el nuevo hogar de la mente. Pero al ser consciente de que está desafiando poderosos intereses económicos y políticos, expresa con vehemencia:

El Ciberespacio no se halla dentro de vuestras fronteras. No penséis que podéis construirlo, como si fuera un proyecto público de construcción. No podéis. Es un acto natural que crece de nuestras acciones colectivas [...] Nuestro mundo está a la vez en todas partes y en ninguna parte, pero no está donde viven los cuerpos (Barlow, 1996, p. 1).

Plantear el ciberespacio como un acto natural resultante de la acción colectiva, implica ir todavía más allá, de modo que podamos considerarlo como un espacio que ha permitido desplegar una serie de prácticas y formas de habitar que lo desbordan, dando lugar a nuevas formas de asociación que se autodenominan 
virtuales, y también a un sinnúmero de experiencias que fungen como oberturas de lo que conocemos como realidad virtual.

Para aproximarnos a la noción de ciberespacio y al mundo virtual que le es inherente, nos apoyaremos en la noción de espacio antropológico del conocimiento, propuesta por el filósofo francés, Pierre Lévy en su libro Inteligencia colectiva. Por una antropología del ciberespacio (Lévy, 2004). De acuerdo con este autor, con el advenimiento del espacio antropológico del conocimiento se produce una revolución en las relaciones sociales, culturales, económicas, políticas y de conocimiento. Lévy ha definido el espacio antropológico como "un sistema de proximidad (espacio) propio del mundo humano (antropológico) y por consiguiente, dependiente de las técnicas, de las significaciones, lenguaje (sic), la cultura, las convenciones, las representaciones y las emociones humanas" (Lévy, 2004, p. 15), y el espacio antropológico del conocimiento como un:

\begin{abstract}
Horizonte nuevo de la civilización" en el cual "la novedad (...) es al menos triple; tiene que ver con la evolución de los conocimientos, con la masa de personas llamadas a aprender y a producir nuevos conocimientos y tiene que ver, en fin, con la aparición de nuevos instrumentos (los del ciberespacio), capaces de hacer surgir bajo la bruma de la información paisajes inéditos y distintos, identidades singulares propias de este espacio y nuevas figuras sociohistóricas (Lévy, 2004, p. 16).
\end{abstract}

En ese sentido, el espacio antropológico del conocimiento hace posible el nacimiento de una dimensión espacial abstracta, construida por el hombre como un recurso tecnológico generado de forma virtual, en cuanto se superpone a los espacios antropológicos anteriores: la tierra, el territorio y el mercantil, es decir, los espacios tangibles. Pero Lévy aclara que:

Lo virtual, en un sentido estricto, tiene poca afinidad con lo falso, lo ilusorio o lo imaginario. Lo virtual no es, en modo alguno, lo opuesto a lo real, sino una forma de ser fecunda y potente que favorece los procesos de creación, abre horizontes, cava pozos llenos de sentido bajo la superficialidad de la presencia física inmediata (Lévy, 1999, p. 8).

Estas definiciones nos aproximan a la noción de ciberespacio que constituye uno de los objetos de nuestro interés, y también nos remiten a los desarrollos teóricos sobre el espacio, la realidad virtual y el internet. Estos dos últimos están estrechamente relacionados con el ciberespacio, por cuanto, junto con éste, se configuran a partir de los actores que involucran y las relaciones que se establecen entre los mismos. En este sentido, cobra gran importancia el tejido social virtual derivado del ciberespacio, así como sus usuarios o habitantes -que en cierto sentido pueden equipararse con los cíborgs de la ciencia ficción ${ }^{7}-$ y sus

\footnotetext{
${ }^{7}$ Del inglés cyborg, acrónimo de cybernetic organism, "organismo cibernético". "Ser formado por materia viva y dispositivos electrónicos". Diccionario de la Real Academia Española, 23ạ Edición.
} 
comunidades virtuales. Sin embargo, sólo podremos ocuparnos de las prácticas e intercambios que surgen en el ciberespacio cuando logremos acercarnos un poco más a la comprensión del término.

\section{Peculiaridades del ciberespacio}

La revisión de las aproximaciones teóricas a la noción de ciberespacio nos permite constatar que no disponemos de una definición única y omnicomprensiva. Por este motivo, debemos examinar algunas interpretaciones acerca de este fenómeno, las cuales proceden de múltiples dominios, a saber, la estética, la antropología cultural, la filosofía de la técnica y la ciencia, la cibernética, las ciencias matemáticas y las ciencias de la comunicación, entre otras disciplinas.

Para comenzar, encontramos que la etimología de la palabra ciberespacio nos remite a las expresiones griegas Kyber y Cybernao; la primera significa navegar y la segunda, pilotar. Como se sabe, sólo se navega a través de un medio fluido y sólo puede pilotarse una nave, por lo cual, en principio, el ciberespacio se puede definir como un espacio navegable y controlable. Por lo dicho anteriormente, este espacio también se caracteriza por ser social y, sobre todo, virtual. Si enlazamos cada uno de los elementos aludidos, encontraremos que el ciberespacio se despliega mediante cierto tipo de comunicación que sólo se puede establecer haciendo uso de dispositivos electrónicos operados por los navegantes o usuarios, los cuales se encuentran localizados en distintos lugares del mundo y están interconectados en una red informática global que, por lo demás, tiene un crecimiento vertiginoso y, al parecer, imparable.

Con la acelerada expansión de las redes informáticas y los dispositivos electrónicos, el acceso al ciberespacio admite, cada vez, más usuarios, llegando a configurarse como un "espacio inestable de las interacciones entre conocimientos y conocientes [sic] de colectivos inteligentes desterritorializados" (Lévy, 2008, p. 18) que se sirve de la red Internet para acercar a todos los usuarios posibles, a un universo de múltiples posibilidades de acción desde la distancia o -para utilizar la ilustrativa expresión de Sloterdijk- actio in distans ${ }^{8}$.

\footnotetext{
${ }^{8}$ Con la expresión actio in distans (acción a distancia), el filósofo alemán Peter Sloterdijk se refiere a las acciones telecomunicativas, esto es, un tipo de acciones que afectan a destinatarios que no se encuentran en la misma coordenada espacio temporal del actor, sino que se encuentran separados de éste, bien sea por el espacio, por el tiempo o, por ambos. En este sentido, la expresión alude a experiencias que se producen en contextos diferentes a aquellos en los cuales fueron generadas, para lo cual se valen de la mediación de alguna clase de dispositivo tecnológico que permite la transferencia. Lo interesante es que pese a que la acción no acaece en el aquí y en el ahora del receptor, es percibida por éste como real y posee la potencia suficiente para generar efectos perceptibles y ocasionar consecuencias específicas. (Sloterdijk, 2008).
} 
Indiscutiblemente, el Ciberespacio se gesta gracias a los procesos comunicativos asociados a Internet; sin embargo, sólo se puede actualizar mediante las interacciones y formas de habitarlo que los navegantes establecen. En este sentido, es posible caracterizarlo como medio y como espacio; una doble condición que lo presenta como un universo desbordante en nuevas experiencias. Este universo permite que los navegantes se encuentren en el ciberespacio, ese lugar intangible que ofrece la posibilidad de conectarse a la red global, en tiempo real y sin límites espacio-temporales, produciendo unos efectos tan vívidos como los que solemos experimentar, en nuestro cotidiano accionar, en los diferentes espacios tangibles o proximales en que nos movemos.

El filósofo alemán Peter Sloterdijk, plantea que el ciberespacio da lugar a una sociedad global en donde lo que cuenta es "una transferencia de pensamientos desregulada de cierta manera, y mixta, en dirección horizontal y vertical, a través de medios simultáneamente comunicativos e informativos" (Sloterdijk, 2008, p. 31). Plantea, además, que con el desarrollo de este universo electrónico, se evidencia una densificación del mundo, derivada de la híper-producción de interacciones; así como una tele-vecindad que supera los límites espacio-temporales que tradicionalmente acompañaban a la geografía del mundo proximal, y que abre paso a una especie de aldea global secularizada. Así presenta Sloterdijk la que podría considerarse, una apocalíptica visión, sobre esta nueva realidad:

En este proceso, la verticalidad es reemplazada cada vez más por la horizontalidad, hasta que se llega a un punto desde el cual los participantes comprenden en los juegos de sociedad que son comunicativos e informativos, que ya nada les llega desde arriba y que están, con sus cerebros, sus medios, sus equivocaciones y sus ilusiones, solos en este mundo desencantado. Están condenados a una ciudadanía mundial electrónica cuyas categorías son dadas mediante los hechos de la densificación del mundo y de la televecindad de todos con todos (Sloterdijk, 2008, p. 31).

Vemos que la postura de Sloterdijk dista de ser tecnofílica o -para evocar la afortunada dicotomía de Umberto Eco (1984) - integrada, inclinándose más hacia el polo apocalíptico. Como se ve, describe, con una diáfana crudeza, el estado actual de los procesos comunicativos para los usuarios de las nuevas tecnologías, que, gracias a ellas, se pueden permitir el lujo de accionar desde la distancia dentro de un mundo desterritorializado y, para colmo, hacerlo en tiempo real. Todo ello, abandonados a su suerte, por los efectos colaterales del retiro de los dioses que se expresa en ese desencantamiento del mundo del que otrora hablara Weber (Weber, 1999), y que tiene como trágico desenlace, el que cada quién tenga que habérselas consigo mismo sin contar con nadie más. 
En contraste con Sloterdijk, Lévy concentra gran parte de sus esfuerzos investigativos en la definición y caracterización del ciberespacio, pero bajo una óptica diferente -quizá más optimista o, si se quiere, integrada-, como se pone en evidencia cuando dice que "el ciberespacio constituye un campo vasto, abierto, aun parcialmente indeterminado, que no se debe reducir a uno solo de sus componentes. Permite interconectar y proveer de una interfase para todos los dispositivos de creación, de grabación, de comunicación y de simulación" (Lévy, 2004, p. 71). Lévy ofrece una interpretación no catastrofista sobre el maremágnum de fenómenos digitales que inundan el mundo contemporáneo, entre ellos el ciberespacio; plantea que la virtualización es el eje central de la transformación que vivimos y que se puede entender como la continuación de la hominización, explicando que "la virtualización no es ni buena, ni mala, ni neutra. Se presenta como el movimiento del "convertirse en otro» -o heterogénesis de lo humano-" (Lévy, 1999, p. 14). Lévy no se limitará a definir el Ciberespacio, únicamente, en términos técnicos y tecnológicos. Da un paso más allá, y describe este espacio, en relación con el tejido social virtual, como una especie de ágora virtual. En su trabajo sobre la inteligencia colectiva presenta esta propuesta, y plantea que las transformaciones del vínculo social, derivadas del ciberespacio, dan lugar a un tejido social virtual, de carácter cooperativo, que impactará positivamente los intercambios entre navegantes. Es evidente que la postura de Lévy está lejos de ser apocalíptica y, antes bien, tiene un acentuado tinte democrático, quizás un tanto idealista -hay que decirlo-, como se puede constatar cuando afirma que:

El ciberespacio cooperativo debe ser concebido como un verdadero servicio público. Este ágora virtual facilitaría la navegación y la orientación en el conocimiento; favorecería los intercambios de saber; acogería la construcción colectiva del sentido; ofrecería visualizaciones dinámicas de las situaciones colectivas; en fin, permitiría la evaluación multicriterio en tiempo real de una enorme cantidad de proposiciones, de informaciones y de procesos en curso (Lévy, 1999, p. 45).

\section{Realidad de la virtualidad}

Debe insistirse en que, a diferencia de lo que suele creerse, lo virtual, bajo ninguna circunstancia, debe ser asociado con lo falso, lo ilusorio o lo imaginario; tampoco debe entenderse como contrario a lo real porque, más allá de ese tipo de interpretaciones apresuradas, encontramos en lo virtual "una forma de ser fecunda y potente que favorece los procesos de creación, abre horizontes, cava pozos llenos de sentido bajo la superficialidad de la presencia física inmediata" (Lévy, 1999, p. 14). 


\subsection{Lo virtual no es lo posible}

Cabe afirmar que ésta no es la primera aproximación plausible a la comprensión de lo virtual, porque tres décadas antes de que Lévy pusiera el tema sobre el tapete, Gilles Deleuze dedicó algunas páginas de su obra Diferencia y repetición a la reflexión sobre este término. Allí aclaraba que no podía entenderse la noción de virtual a partir de un análisis comparativo frente a lo real, porque el primero no se oponía al segundo, sino que evidenciaba que existía otra forma de ser, explicándolo así:

Lo virtual no se opone a lo real, sino tan sólo a lo actual. Lo virtual posee una realidad plena, en tanto es virtual. De lo virtual es preciso decir exactamente lo que Proust decía de los estados de resonancia: «Reales sin ser actuales, ideales sin ser abstractos»; y simbólicos, sin ser ficticios. Lo virtual hasta debe ser definido como una estricta parte del objeto real, como si el objeto tuviera una de sus partes en lo virtual, y se sumergiera allí como en una dimensión objetiva (Deleuze, 2004, p. 314).

No oponer lo virtual a lo real suscita el interrogante sobre qué sería, entonces, lo opuesto a cada uno, o mejor, cuál sería su par lógico. En este caso, comenzaremos con lo que creemos percibir como más inmediato y diáfano para nuestros sentidos: lo real. De esta forma, debemos considerar primero la relación que existe entre lo real y lo posible. Básicamente, lo posible preexiste y se realizará sin que nada afecte su futura existencia, se trata de un real latente, al que sólo le falta la existencia. Deleuze explicaba con plena claridad que: "Lo posible se opone a lo real; el proceso de lo posible es, por consiguiente, una «realización»" (Deleuze, 2004, p. 318). Esta imposibilidad de concebir lo virtual como opuesto a lo real nos presenta un nuevo obstáculo porque, evidentemente, el camino más fácil para nuestra cognición es considerar lo virtual como irreal y creer que es algo ilusorio que engaña nuestros sentidos. Al identificar esta tendencia facilista, Deleuze se puso en la tarea de esclarecer la duda, tal vez razonable, y postula que lo virtual puede entenderse como el carácter de la idea, explicando que "es a partir de esa idea que se produce la existencia, y se produce conforme con un tiempo y con un espacio inmanentes a la idea" (Deleuze, 2004, p. 319). Ahora bien, el lector podría considerar que esta observación no es lo suficientemente clara y que, al llevar el análisis al orden de las ideas, sería válido pensar como análogos lo virtual y lo posible. Sin embargo, Deleuze fue contundente al diferenciarlos, a pesar de concebirlos ambos desde el orden de las ideas; así continúa con su explicación sobre su diferencia con las siguientes palabras:

Lo posible y lo virtual también se distinguen porque uno remite a la forma de identidad en el concepto, mientras que el otro designa una multiplicidad pura en la Idea, que excluye radicalmente lo idéntico como condición previa. En fin, en la medida en que lo posible se propone a la «realización», es él mismo concebido como la imagen de lo real; y lo real, como la semejanza de lo posible. Por ello se entiende tan mal qué es lo que la existencia agrega al concepto al duplicar lo semejante por lo semejante (Deleuze, 2004, p. 319). 
Vemos cómo lo posible se puede entender mejor como algo parecido, que sólo puede ser identificado con posterioridad a la manifestación de lo real. Sería como una imagen anticipada, pero de ninguna manera revelada a priori, de lo que se ha realizado. Indiscutiblemente, la aparición de lo posible sólo se da tras esa realización que permitirá considerar a cuál posibilidad le dio existencia. En esta relación entre real y posible, definitivamente, se puede entender que está implícita la semejanza; en cambio, en la relación entre lo virtual y lo actual, encontramos, de manera insospechada, que media la diferencia, como enfatiza Deleuze:

La actualización de lo virtual siempre se hace por diferencia, divergencia o diferenciación [différenciation]. La actualización rompe tanto con la semejanza como proceso, como con la identidad como principio. Nunca los términos virtuales se asemejan a la virtualidad que actualizan [...] la actualización, la diferenciación, siempre son una verdadera creación que no se hace por limitación de una posibilidad preexistente (Deleuze, 2004, p. 319).

De este modo, el proceso de actualización es creador e innovador y, por ende, no se reduce a darle solución a algún problema mediante la realización de una opción entre varias. La actualización de lo virtual no es unívoca, no es como seleccionar una carta de la baraja puesto que, en cualquier momento, podrían surgir nuevas actualizaciones imprevistas, como claramente lo señala Deleuze:

Para algo potencial o virtual, actualizarse siempre es crear las líneas divergentes que se corresponden sin semejanza con la multiplicidad virtual. A lo virtual le corresponde la realidad de una tarea por cumplir o de un problema por resolver; el problema es el que orienta, condiciona, genera las soluciones; pero estas no se asemejan a las condiciones del problema [...] La diferencia y la repetición en lo virtual fundan el movimiento de la actualización, de la diferenciación como creación, sustituyendo así a la identidad y a la semejanza de lo posible, que sólo inspiran un seudomovimiento, al falso movimiento de la realización como limitación abstracta (Deleuze, 2004, pp. 319-320).

\subsection{Lo posible y lo virtual en escena}

La diferencia entre lo posible y lo virtual se puede observar con claridad, al contrastar ciertos aspectos de dos películas que, por lo demás, tratan temáticas bastante diferentes: por un lado, tenemos la película Next ${ }^{9}$, protagonizada por el actor estadounidense Nicolas Cage, que se despliega siguiendo el curso de lo posible y, por otro, ante la imposibilidad de encontrar una película cuya trama tenga como hilo conductor la cuestión lo virtual, nos conformaremos con una de las historias tratadas en la película Decamerón del cineasta italiano Pier Paolo Passolini, aclarando, eso sí, que nuestro propósito no es realizar un análisis en

\footnotetext{
9 Traducida como "El vidente".
} 
profundidad de tales filmes, sino utilizarlos sólo a manera de ejemplos, de los dos conceptos tratados.

En el primer caso, tenemos que Cris Johnson (Nicolas Cage) es un vidente que puede prever el futuro que le puede afectar, con un margen de anticipación que puede abarcar, dependiendo de ciertas condiciones, desde unos cuantos minutos hasta un tiempo mucho mayor de alcance indefinido. La cuestión es que se enamora de una mujer a la que había anticipado en sus visiones, la cual magnifica con su cercanía el poder visionario de Cris, al tiempo que termina involucrada en sus peligrosas aventuras, al punto de que el futuro le depara un final bastante trágico, en caso de realizarse ciertas posibilidades que habrían sido rigurosamente calculadas por la mente de Cris. La película nos muestra el final desastroso que tendrían los protagonistas si Cris tomara la decisión de huir de sus perseguidores (agentes del FBI que lo buscan para aprovecharse de sus dotes de vidente en la prevención de un atentado terrorista). Al final, nos enteramos de que todo eso solo fueron visiones premonitorias de largo alcance y podemos contemplar a Cris entregándose a los agentes, con la condición de que se le brinde protección a su novia Liz. A partir de aquí, no sabemos qué sucede y desconocemos cuál de todas las posibilidades alcanza su realización. En todo caso, será una ya prevista por Cris. Este, pues, es un claro ejemplo de realización de una posibilidad.

En el segundo caso, nos encontramos ante las vicisitudes de un pintor (caracterizado por el propio Pasolini) a quien se le ha encargado la misión de pintar un gran mural en el interior de una catedral. Trabaja incesantemente durante días en los bocetos sin mucha convicción, hasta que tiene un sueño donde se le presenta en todo su esplendor una imagen desbordante de colorido y belleza. Durante el sueño, el pintor se siente como si hubiese sido transportado ante las mismas puertas del cielo: tan vívida es su experiencia, tan intensas son sus sensaciones. Al despertar no consigue retener los detalles de su fantástico sueño y sufre el desconcierto ocasionado por la sensación de que algo fundamental se le ha escapado en su recuerdo. Su inspiración parece haberlo abandonado, viéndose obligado a suspender el avance de la obra, y sus aprendices se entregan al ocio, mientras esperan las nuevas órdenes de su maestro. Cuando recibe algún destello de su sueño, corre presuroso arrastrando tras de sí a sus ayudantes para ponerse manos a la obra antes de que se le vuelvan a escapar los precarios fragmentos. De esta forma, luego de muchas interrupciones, logra finalizar la pintura, pero en medio de la celebración, termina decepcionado al concluir que ésta no consiguió captar la esencia de su sueño, y se dice para sí: "Pero yo me pregunto: ipor qué realizar una obra cuando es más bello soñarla solamente?" Aunque Pasolini utiliza la palabra realizar, tenemos aquí un claro ejemplo de la actualización de la virtualidad. 


\section{La virtualización: una forma de ser real de otro modo}

Retomemos lo que hasta ahora se ha planteado: lo posible puede entenderse como algo ya estructurado, mientras lo virtual existe potencialmente. El carácter de lo virtual sólo puede entenderse si se concibe como una red de problemas y tendencias inherentes a cualquier entidad, que además requieren de una solución creadora y creativa: la actualización. La relación que establecen lo virtual y la entidad sería bidireccional, en tanto la entidad produce sus virtualidades y lo virtual constituye la entidad.

Ahora podemos poner a Pierre Lévy en perspectiva, señalando cómo, de la mano de Deleuze, nos aporta una interesante interpretación sobre la cuestión, al proponer que lo actual, en lugar de parecerse a lo virtual, responde a sus demandas. En este orden de ideas, se puede inferir que la actualización sería, entonces, la creación de una solución que se espera ante un cúmulo de problemas, y la realización, por su parte, sería la materialización de un posible que ya estaba preestablecido.

Siendo lo actual el par lógico de lo virtual, la actualización también deberá tener un inverso, que no sería otro que la virtualización, la cual no debe entenderse como una desrrealización, sino como una transformación ontológica de la entidad, la que pasaría del campo de la solución al campo problemático. Lévy logra descifrar la lógica del proceso de virtualización de cualquier entidad, explicando que el punto de partida es averiguar cuál es el problema o interrogante que se resolvió con la actualización de la entidad, para luego dar lugar a un nuevo proceso que consiste en "mutar la entidad en dirección a este interrogante y en redefinir la actualidad de partida como respuesta a una cuestión particular" (Lévy, 1999, p. 19).

En verdad, la virtualización es una noción bastante problemática y dificulta la comprensión de lo virtual y lo actual. En principio, sólo es necesario asimilar que lo virtual existe en potencia como una serie de problemas que buscan solución mediante un proceso creador de actualización; sin embargo, la dificultad surge cuando hay que inferir cómo opera el proceso inverso. Surge el interrogante acerca de si es posible que exista una operación que permita ir de lo actual a lo virtual. Para responder esta inquietud, será necesario, una vez más, acudir a Pierre Lévy, quien responde la inquietud de la siguiente manera:

La actualización iba de un problema a una solución. La virtualización pasa de una solución dada a un (otro) problema. Transforma la actualidad inicial en caso particular de una problemática más general, en la que está integrada, desde ahora, el acento ontológico [...] Implica tanta irreversibilidad en sus efectos, indeterminación en sus procesos e indeterminación en su esfuerzo como la actualización (Lévy, 1999, p. 20). 
Una vez se ha aclarado que lo virtual también es real, deberemos especificar que aquello puede entenderse como otro modo de ser que complementa a lo tangible siendo, a un tiempo, imperceptible a los sentidos. Esta condición nos lleva a otra situación propia de la fenomenología virtual: el no estar ahí, es decir, la disyunción del hic et nunc, la separación del aquí y el ahora, como observa Lévy cuando dice que:

La virtualización somete el relato clásico a una dura prueba: unidad de tiempo sin unidad de lugar (gracias a las interacciones en tiempo real a través de redes electrónicas, a las retransmisiones en directo, a los sistemas de telepresencia), continuidad de acción a pesar de duración discontinua (como en la comunicación por medio de los contestadores automáticos o de las mensajerías electrónicas) (Lévy, 1999, p. 22).

La virtualización opera como un movimiento que transforma por completo la realidad, sin que deje de existir; pero sí tomando otra forma de ser que, a pesar de no tener una ubicación espacial, sí se despliega en el tiempo y genera efectos reales. Es inevitable, entonces, asociar la desterritorialización a lo virtual, debido a que su operación, la virtualización, se mueve más allá del aquí y del ahora. Esta trascendencia de la relación ordinaria espacio-tiempo, nos abre las puertas a un universo de lo virtual, donde surgen otras formas de interacción con temporalidades y espacialidades distintas. Una muestra de ello es el ciberespacio, el cual, rebosa de virtualidad al ofrecer una multiplicidad de espacios, gracias a la interconexión; y una nueva temporalidad, mediante la sincronización. Así presenta Lévy la salida del ahí, implícita en el ciberespacio: "La virtualización no se contenta con acelerar los procesos ya conocidos, ni con poner entre paréntesis, incluso con aniquilar, el tiempo o el espacio, como pretende Paul Virilio, sino que inventa, con el consumo y el riesgo, velocidades cualitativamente nuevas y espacios-tiempo mutantes" (Lévy, 1999, p. 22).

Desde esta línea de pensamiento, sería válido considerar que el ciberespacio es una virtualización del espacio, en tanto ofrece una multiplicidad de redes que se configuran como nuevos y desterritorializados espacios de proximidad, que invitan a los navegantes nómadas a que accedan a ellos en tiempo real, para encontrarse con que no se está ahí, ni se está ahora; no se está adentro, como tampoco se está afuera; no es claro si se pasa del interior al exterior o viceversa.

He aquí la heterogénesis de la alteridad. El ciberespacio ha dado lugar a la configuración de una especie de banda de Moëbius, es decir, a una continuidad entre lo interior y lo exterior y, por ende, entre el tiempo y el espacio. Obviamente, algo ha cambiado en nuestro modo de habitar el mundo: quienes accedemos habitualmente a los flotantes dominios del ciberespacio, ya no estamos ante aquel espacio newtoniano que interpretamos meramente como un afuera. Antes bien, nos encontramos frente a un dramático volcamiento hacia adentro. Hemos sido arrojados a la cíber-esfera. Pero esa cuestión la dejaremos para otra ocasión. 
Figura 1. Banda de Moebius

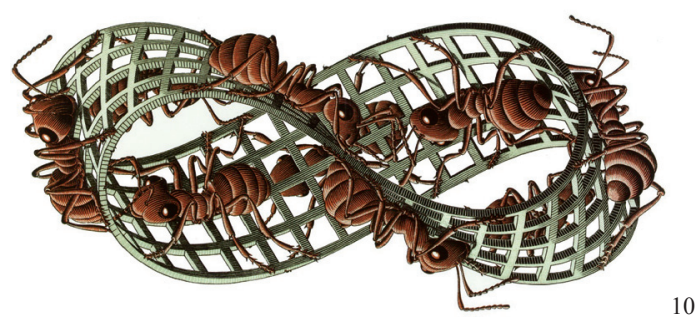

Fuente: Maurits Cornelis Escher, 1963

\section{Anexo \\ Ajedrez II Jorge Luis Borges}

Tenue rey, sesgo alfil, encarnizada reina, torre directa y peón ladino sobre lo negro y blanco del camino buscan y libran su batalla armada.

No saben que la mano señalada del jugador gobierna su destino, no saben que un rigor adamantino sujeta su albedrío y su jornada.

También el jugador es prisionero (la sentencia es de Omar) de otro tablero de negras noches y de blancos días.

Dios mueve al jugador, y éste, la pieza. ¿Qué Dios detrás de Dios la trama empieza de polvo y tiempo y sueño y agonía? $\varphi$ 


\section{Referencias}

Baudrillard, J. (1984). Cultura y Simulacro. Barcelona: Kairós.

Derrida, J. (2011). Khôra. Buenos Aires: Amorrortu.

Eco, U. (1984). Apocalípticos e integrados. España: Lumen.

Gibson, W. (2006). Neuromante. España: Minotauro.

Deleuze, G. (2004). Diferencia y Repetición. Buenos Aires: Amorrortu.

Lévy, P. (1999). ¿Qué es lo virtual? España: Paidós.

Sloterdijk, P. (2003). Esferas I. Burbujas. España: Siruela.

Sloterdijk, P. (2008). Actio in distans. Sobre los modos de formación teleracional del mundo. Nómadas, (28), 22-33.

Sloterdijk, P. (2009). Esferas III. Espumas. España: Siruela.

Wachowski, L. y Wachowski, A. (1999). Película: The Matrix. Estados Unidos: Village Roadshow Pictures-Silver Pictures.

Wachowski, L. y Wachowski, A. (2003). Película: The Matrix Reloaded. Estados Unidos: Village Roadshow Pictures-Silver Pictures.

Wachowski, L. y Wachowski, A. (2003). Película: The Matrix Revolutions. Estados Unidos: Village Roadshow Pictures-Silver Pictures.

Weber, M. (1999). La ética protestante y el espíritu del capitalismo. Barcelona: Península.

\section{Cibergrafía}

Barlow, J.P. (1996). “Declaración de independencia del ciberespacio". Recuperado de http://homes.eff.org/ barlow/Declaration-Final.html (Consultado el 12 de diciembre de 2014).

Escher, M.C. (1963). Cinta de Moebius. Recuperado de https://quinnae. com/2012/06/17/its-just-a-game-the-discursive-construction-of-the-virtual/ (Consultado el 12 de diciembre de 2014). 
Lévy, P. (2004). "Inteligencia colectiva. Por una antropología del ciberespacio". Washington DC: Organización Panamericana de la Salud. Recuperado de: http:// inteligenciacolectiva.bvsalud.org/public/documentspdf/es/inteligenciaColectiva. pdf (Consultado el 04 de marzo de 2010).

Lévy, P. (2007). Cibercultura. La sociedad digital. España: Anthropos, México: Universidad Autónoma Metropolitana.

Wallace, W. D. (2011). Interviews. William Gibson. En The Art of Fiction, (211). Recuperado de http://www.theparisreview.org/interviews/6089/the-art-of-fictionno-211-william-gibson (Consultado el 12 de diciembre de 2014). 